\title{
Un análisis del programa de becas Ser Pilo Paga: apuntes sobre desigualdades y fronteras de clase social en Colombia
}

\author{
Bacca Contreras, Rafael Eduardo \\ Un análisis del programa de becas Ser Pilo Paga: apuntes sobre desigualdades y fronteras de clase social en \\ Colombia \\ Revista Educación, vol. 45, núm. 1, 2021 \\ Universidad de Costa Rica, Costa Rica \\ Disponible en: http://www.redalyc. org/articulo.oa?id=44064134004 \\ DOI: https://doi.org/10.15517/revedu.v45i1.40902
}

Esta obra está bajo una Licencia Creative Commons Atribución-NoComercial-SinDerivar 3.0 Internacional. 


\title{
Un análisis del programa de becas Ser Pilo Paga: apuntes sobre desigualdades y fronteras de clase social en Colombia
}

\author{
Analysis of the Ser Pilo Paga Scholarship: Notes on Inequities and Social Class Boundaries in Colombia \\ Rafael Eduardo Bacca Contreras \\ Universidad Industrial de Santander, Colombia \\ rafaelbacca08@gmail.com \\ DOI: https://doi.org/10.15517/revedu.v45i1.40902 \\ Redalyc: http://www.redalyc.org/articulo.oa?id=44064134004
}

iD http://orcid.org/0000-0001-9939-9258

Recepción: 14 Abril 2020

Aprobación: 12 Agosto 2020

\section{ReSUMEN:}

A partir de una aproximación sobre algunas políticas estatales de inclusión a la educación superior en sectores sociales mediosbajos y bajos colombianos, se establece el marco en el cual nace el programa Ser Pilo Paga. En segundo término, se desarrolla un despliegue de dicho programa prestando atención a sus aristas sociales y económicas. Con ello, se da paso al planteo de las tensiones de clase social en tanto muchas de las personas elegidas de este programa han seleccionado universidades privadas (algunas de élite) para educarse. Metodológicamente, se hace uso de entrevistas y testimonios elaborados por algunos/as investigadores/as y medios periodísticos a beneficiarios/as; con lo cual se apoya vislumbrar esas tensiones. Para terminar, se reflexiona sobre las condiciones y tensiones de desigualdad social en lo educativo en Colombia desde las clases sociales y se plantean interrogantes que rondan un programa que pudo y puede ser más equitativo y eficiente.

Palabras Clave: Colombia, Clases sociales, Desigualdad social, Educación superior, Programa Ser Pilo Paga .

\section{Abstract:}

The framework of the Colombian Ser Pilo Paga program was established on the basis of certain state policies aimed at lowermiddle and lower-income social sector inclusion in higher education. This program was developed with specific attention on social and economic aspects. Social class tension is associated to the fact that many of the students selected for this program ultimately chose to attend private universities (including elite institutions). The study methodology is conducive to obtaining a glimpse at the resulting tension based on interviews and eyewitness accounts from scholarship recipients interviewed by researchers and the media. The author concludes by reflecting on the conditions and pressure aligned to social inequities at schools in Colombia from a social class perspective and questions a program that could and should have been fairer and more efficient.

KEYWORDs: Colombia, Social Classes, Social Inequity, Higher Education, Ser Pilo Paga Scholarship.

\section{INTRODUCCIÓN}

Las sociedades relativamente igualitarias se conectan virtuosamente, grosso modo, con sistemas educativos que propenden por una movilidad social ascendente. A diferencia de sociedades desiguales en las cuales el sistema educativo tiende a reproducir las desigualdades sociales (García y Quiroz, 2011; Mendes, 2016). Si bien esta afirmación es esquemática, mecánica, no por ello pierde validez como marco de partida para la actual aproximación sobre el programa Ser Pilo ${ }^{[1]}$ Paga (en adelante SPP).

En este ámbito, Colombia se presenta como una de las sociedades con mayor desigualdad mundial: para 2018 se registraba como el octavo país más desigual del planeta y el segundo en el continente, después de Haití y junto a Honduras, según el índice de Gini del Programa de Naciones Unidas para el Desarrollo (Círculo de Estudios Latinoamiercanos [Cesla], 2019). En una entrevista al diario colombiano El Espectador (Redacción Negocios y Economía, 2016) Thomas Piketty afirma que existen ciento por ciento de probabilidades de que el hijo o la hija de una familia rica vaya a la universidad, pero cero por ciento de que lo haga el de una familia pobre. Aunque este dictamen es cuasiapocalíptico o pesimista, es de rescatar que no es una preocupación 
disparatada en un país en que el ingreso per cápita del 10\% más rico equivale a 24 veces el del 30\% más pobre, según la misma entrevista.

Este diagnóstico es reiterativo en los estudios sobre desigualdad y educación en Colombia puesto que es un condicionamiento estructural (García y Quiroz, 2011; Cataño, 1984). Ahora bien, a pesar de que en algunos periodos la repartición de la riqueza, mediada por instrumentos estatales principalmente, ha posibilitado mayor movilidad social y una sociedad un poco más equitativa, las posibilidades de ascenso social han sido pocas $^{[2]}$.

Además de alta desigualdad, Colombia se caracteriza por su baja movilidad social en términos de una alta correlación entre la educación de padres e hijos, similar a la de Brasil y más alta que la de otros países también desiguales como México (Angulo, 2012, citado por Álvarez, 2019, p.4).

En relación con el sistema educativo, algunas políticas públicas han intentado promover un mayor acceso a la educación superior de sectores excluidos estructuralmente. Pretendiendo, entre otras cosas, democratizar la educación y desincentivar la reproducción social (Álvarez et al., 2017; Londoño, 2016).

En referencia a esto último, los programas estatales hacia la democratización de la educación superior han pretendido primordialmente mitigar la brecha de acceso y, en algunos casos, abordar la permanencia (Vizcaíno y Amaya, 2006). Aunque indudablemente ciertos programas han sido más influyentes y eficientes que otros - en los dos próximos apartados se analizarán detalladamente- lo que a este texto compete es intentar dilucidar - lo cual se efectúa en la tercera parte desde una articulación de clases sociales y desigualdad social - ciertos conflictos de clase en escenarios de sociabilidad educativa surgidos con el programa SPP.

\subsection{Marco teórico}

Los estudios sobre desigualdades sociales, instituciones educativas y ámbitos de sociabilidad de distintos sectores sociales recorren este estudio. Uno de los pilares de este trabajo lo marca publicaciones clásicas como lo de Bourdieu y Passeron (1977), La reproducción. Elementos para una teoría del sistema de enseñanza, marcan una herencia fuerte en aras de observar a la institución educativa como reproductora de las desigualdades sociales. Desde esta óptica analítica, para el caso de Colombia Rama (1970) presenta a la formación educativa de élites en un sentido endogámico con respecto a ciertas instituciones educativas privadas nacionales. Por su parte, el artículo de Sandoval (2011) desarrolla un estudio del campo educativo en Colombia retomando lo que hacen los sociólogos franceses antes mencionados para Francia. Algo similar expresan Vizcaíno y Amaya (2006), Sánchez y Otero (2012) y Díaz (2012) resaltando el prestigio que representa la profesión por sobre las carreras técnicas o tecnológicas y las identificaciones de ciertos grupos sociales con ellas en Colombia.

Desde una perspectiva similar, pero ahondando en sectores medios-bajos y bajos, los cuales son los que más interesan a este texto, se recuperan investigaciones como las de García y Quiroz (2011), Mora y Múnera (2018) y De Zubiría (2016). En estos se configura un panorama histórico del acceso limitado a la educación superior en el país, además es posible entrever algunas de las repercusiones de clase social debido al choque social de programas como SPP. Asimismo, se afirma que algunos programas profundizan el problema y no son lo suficientemente contundentes para dar una apertura democrática; en esta insuficiencia encuentran a SPP.

Ahora bien, desde el otro pilar teórico se pueden observar estudios que desarrollan la inclusión de sectores sociales medios-bajos y bajos desde sus ámbitos de sociabilidad y, también, relacionan ese ingreso educatvio virtuosamente a una mayor movilidad social. Ejemplo de ello es el estudio de Kerbo (2004), en donde se hace explícito que mediante las motivaciones, preferencias y destrezas individuales se pueden desplazar los individuos hacia arriba en el eje social de clases. Lo propio intenta demostrar Belleï (2002) con la Reforma Educacional Chilena respecto a sectores menos favorecidos. Este tipo de investigaciones, para el caso 
colombiano, son desarrolladas por Álvarez et al., (2017); Poveda (2019); Arrubla y Uribe (2015); Londoño (2016) y García (2018), en los que también puede notarse que SPP, además de otros programas anteriores, han permitido abrir una ruta más amplia hacia una educación superior más equitativa, con una apertura en la movilidad social y una tolerancia mayor entre clases sociales.

Ahora bien, debido a que buena parte de los textos antes mencionados, y otros como los de Villarraga (2017) y Puentes y Virviescas (2016), se interesan sobre todo por la política pública educativa en los ámbitos de su implementación, intereses políticos o problemas financieros. Para este trabajo se destacan las investigaciones de Álvarez (2019), Solano (2008) y López y Moncada (2012) porque articulan sus investigaciones explícitamente con la clase social a partir de entrevistas, testimonios y, como el texto de Álvarez, observación participante con los/as actores. Es por ello que, para reforzar el análisis de clase social a partir de entrevistas y testimonios, se acude a publicaciones de prensa que han hecho labores afines. La Revista Semana (2019), SemanaEducación (2019) hicieron acercamientos a historias de vida y entrevistas a beneficiarios/as; lo propio forjaron Romero (2018) y Vega (2019) desde otros medios periodísticos.

\subsection{Enfoque}

El enfoque utilizado es el análisis de una política gubernamental de democratización educativa en el nivel superior y las consecuencias de sociabilidad en términos de clases sociales. Se interroga desde el posible reforzamiento de las desigualdades que se pensaban combatir hasta la amplitud de derechos que este programa aporta. En otras palabras, las miras del artículo son claras en cuestionar los alcances y consecuencias, a veces imprevistos, de una política pública de democratización educativa que, basada en el mérito y equidad de oportunidades, presenta tensiones relevantes en términos de interacciones sociales de clase. Por eso, el enfoque particular no tiene tanto que ver con la política pública en sí misma, sino que ahonda en su desarrollo y consecuencias subjetivas desde las relaciones sociales particulares.

Con base en esto último, es importante acotar que el escrito plantea cuestiones que muchas veces van más allá de la formulación e implementación de este tipo de políticas, puesto que controlar las apropiaciones subjetivas o conflictividades grupales nacientes de nuevos escenarios de sociabilidad, como el caso de jóvenes de sectores populares en universidades de élites, es difícil. Lo que sin duda hace parte integrante de la perspectiva aquí propuesta es la advertencia a que, observados algunos alcances negativos de este tipo de políticas, surgen conclusiones en el sentido de tratar de prevenirlas o, en tanto se pueda, intentar no reforzar ciertos rasgos de clase que, en casos particulares, continúan cimentando una sociedad desigual.

\section{A Modo DE CONTEXTO}

Se destacan dos hechos históricos sobre políticas estatales, focalizadas en sectores medios-bajos y bajos, que facilitan el acceso a una Institución de Educación Superior (en adelante IES) colombiana. Por un lado, en 1950 se crea el Instituto Colombiano de Crédito Educativo y Estudios Técnicos en el Exterior (Icetex).

Esta organización fue producto de la tesis de maestría en Administración Pública de Gabriel Betancourt, quien retoma elementos de su experiencia para proponer la creación de una institución autónoma, descentralizada, con personería jurídica y con recursos propios, que facilitara a los estudiantes realizar sus estudios de pregrado y especialización en el exterior, estos debían pagar el crédito una vez regresaran al país. (Poveda, 2019, p. 3)

En este sentido, es con el decreto 3155 de 1968 que la entidad adquiere un carácter administrativo autónomo, un patrimonio propio y vinculado al Ministerio Nacional de Educación (Villarraga, 2017). De ahí sus funciones más amplias para conceder créditos a graduados de la educación media que pretenden ingresar a una IES (Redacción El Tiempo, 2000a; Redacción El Tiempo, 2000b). Respecto a este programa gubernamental, Icetex, Salazar, Mesa y Correa (2016) expresan que sus créditos han tenido una mayor 
demanda en los estratos más bajos, es decir, en los estratos 1,2 y $3^{[3]}$. Estos sectores sociales, debido a sus limitaciones socioeconómicas para acceder a una IES, encuentran en este organismo su vía de acceso para continuar sus estudios.

Desde otra perspectiva,

otro hecho histórico se dio con la Constitución de 1991, la cual en el artículo 67, contempla la educación como un derecho de la persona y un bien público con función social. Asimismo, en el artículo 69, se determina que el Estado será el encargado de proporcionar los medios económicos que permitan el acceso a la educación superior (Poveda, 2019, p. 3).

Estos dos sucesos presentan un panorama de incentivos para que sectores medios-bajos y bajos tengan mayores posibilidades de ingreso a la educación superior. A pesar de que estos dos artículos jurídicos sugieren una garantía educacional, Ramos y Parra (2017) afirman que en las IES falta mucho para concretarlo. Tomando el Estado — así como algunas universidades con políticas internas en el mismo sentido- un papel de garante parcial a través de créditos y/o becas para el ingreso y sostenimiento universitario.

Ahora bien, la forma en que las políticas públicas mencionadas segmentan a las personas jóvenes de último año de la educación media es mediante un examen, en este se pretende sustentar el saber aprendido en las principales áreas del conocimiento (Álvarez, 2019). Antes llamado ICFES y ahora SABER PRO, Bohorquez (2016) explicita que este examen se resume en un puntaje general, contenido de otras puntuaciones particulares por áreas estratégicas: matemáticas, química, física, etc., que permite competir por un cupo en alguna IES.

Otro componente relevante para el acceso a créditos o becas educativas del Estado es el estrato socioeconómico. Esto es, según Uribe (2008), una referencia del Estado para saber las condiciones socioeconómicas de una familia. Basado en una política de subsidios cruzados para Bogotá en los años ochenta, aplicada en los noventa y ampliada a otras ciudades grandes e intermedias del país, los estratos dividen a la sociedad colombiana del 1 al 6. Los dos primeros, 1 y 2, son subsidiados por los tres últimos, 4, 5 y 6 a través de un excedente progresivo en las tarifas de luz, agua, alcantarillado, gas; cabe aclarar que el estrato 3 paga lo consumido. Para determinar a qué estrato se pertenece el Estado se basa en dos aspectos: ubicación de la vivienda y acabados de esta. Vale aclarar que desde que se formuló esta estratificación social su base estadística ha quedado en buena medida desactualizada, debido a que algunas personas son de ciertos estratos, pero viven en mejores o peores condiciones, aun así, se continúa tomando como referencia para determinar potenciales beneficiarios de los programas estatales.

En relación con otro de los programas estatales. En la década pasada existió un programa con mejores condiciones que los créditos del Icetex. Este se denominó Acces (Acceso con Calidad a la Educación Superior). Este programa

\footnotetext{
pretendía atacar las disparidades de acceso a educación post-secundaria. Este, era un préstamo a largo plazo que prestaba hasta el $75 \%$ del costo de la matrícula según el estrato socioeconómico del solicitante, ofrecía una tasa de interés real de $0 \%$ y daba hasta 10 años de plazo para repagar la deuda. El impacto encontrado es de 20\% sobre la probabilidad de acceso a educación superior. (Álvarez et al., 2017, p.7).
}

Acces ha tenido buena valoración en investigaciones de acceso educativo porque se diferenciaba del Icetex esencialmente en las facilidades y viabilidades para su pago (Díaz, 2012; Puentes y Virviescas, 2016). Es decir, la mayor parte de quienes se beneficiaron de Acces pudieron cancelar sus deudas con el Estado en poco tiempo, a diferencia de las personas que accedieron y acceden con Icetex ${ }^{[4]}$.

Lo que estos programas tienen en común es que privilegian la idea de estudiantes pilos/as, sobresalientes en sus resultados de pruebas del Estado. Esta perspectiva, basada en incentivos de competencia y mejoramiento individual para obtener los mejores puestos y beneficios (Kerbo, 2004), presenta ciertos interrogantes en una sociedad tan desigual que, como se expresó antes, dificulta participar por el premio de una beca en condiciones similares. En esta perspectiva, Álvarez et al. (2017) exponen que el gran interrogante de muchas 
investigaciones afines ronda la cuestión de si estos programas abonan un terreno de reproducción de las desigualdades sociales o, por el contrario, democratiza la sociedad a través de lo educativo y potencia una sociedad con mayor movilidad social, más equitativa. Si bien el carácter de este texto es de análisis de interacciones de clase social en contextos educativos, el trasfondo es precisamente el de las formas y los nuevos escenarios que plantean estos programas para acceder a una IES. En este panorama es que precisamente se enmarca el programa de SPP.

\section{Metodología}

Para desarrollar el objetivo planteado, la metodología utilizada se basa en la revisión bibliográfica de libros, artículos científicos, tesis de grado y posgrado, así como entrevistas periodísticas y columnas de opinión. Por un lado, esta revisión habilita la discusión teórica y el repaso histórico que se encuentra en las primeras páginas. De otro lado, la exploración de entrevistas y testimonios surgidas de divulgación científica y periodística a las personas beneficiarias del programa, han permitido armar la articulación central del escrito: un análisis de clase social en ámbitos de sociabilidad educativa entre sectores medios-bajos y bajos y sectores medios-altos y altos.

\section{Las ilusiones de Ser Pilo Paga}

Frente a un panorama de alta desigualdad en el ingreso a la educación superior, en el primer gobierno -2010-2014- de Juan Manuel Santos se decide crear un programa que premie a estudiantes excelentes de la educación media con el ingreso becado a una IES. Este programa, llamado SPP, brinda garantías para el ingreso, la permanencia y otras demandas de la vida universitaria, dando la posibilidad a muchos jóvenes de arar un mejor futuro académico y, en lo posible, laboral. Particularmente, para este mandatario la cuestión educativa se presentó como pilar fundamental de una sociedad más justa y equitativa, ambicionando que el país se convirtiera en el más educado de Latinoamérica en el 2025 (Ramos y Parra, 2017; Villarraga, 2017).

Detalladamente, en los primeros años de gobierno de Santos, la situación educativa era que

cerca del $60 \%$ de los 27,000 puntajes más altos de la prueba Saber $11^{[5]}$ de 2012 eran obtenidos por estudiantes de estrato 1,2 y 3 y que, dos años después de la prueba de Estado, alrededor del 23\% de los jóvenes no habían logrado acceder a una institución de educación superior (IES) por falta de recursos económicos (Álvarez et al., 2017, p. 3).

$\mathrm{Al}$ respecto,

una de las causas principales que impide el ingreso a las instituciones de educación superior está relacionada con los altos costos, esto debido a que las universidades públicas del país solo cubren cerca de $50 \%$ del total de la matrícula, quedando en manos de instituciones privadas la otra mitad (SemanaEducación, 2019, párr. 25).

Frente a esta difícil situación, en los años 2011 y 2012 se comienza a debatir la creación de una política pública que apoye a jóvenes de estratos medios-bajos y bajos con su futuro académico. Este debate se traducirá en un programa, el cual se pone en marcha realmente hasta el segundo semestre de 2014, que tendrá unos requisitos taxativos para elegir solamente a estudiantes más pilos/as y con condiciones socioeconómicas limitadas. Es así que

según el documento Conpes 3914 de 2018, los requisitos básicos para ser beneficiario de SPP incluyen la obtención de un puntaje mínimo en la prueba Saber 11 (310 en el año 2014, 318 en 2015, 342 en 2016 y 348 en 2017); contar con un puntaje SISBEN $^{[6]}$ máximo específico, dependiendo de la zona de residencia al momento de presentar la prueba Saber 11 , y haber sido admitido en una de las IES de alta calidad en el país. (Mora y Múnera, 2018, p. 117). 
Dadas las condiciones, se beneficiaron más de nueve mil jóvenes en su primera edición. No obstante, es poco puesto que "Anualmente en Colombia se gradúan de la educación media, en promedio, 550.000 estudiantes. De ellos, el $93 \%$ pertenecen a los estratos 1, 2 y 3. Por tanto, 480.000 estudiantes necesitan apoyo estatal para poder continuar sus estudios" (SemanaEducación, 2019, párr. 2). De este casi medio millón de jóvenes han sido beneficiados/as, entre 2015 y 2018, unas 40 mil personas, con un costo de unos 1,57 billones de pesos colombianos (Romero, 2018). La situación continúa siendo de desamparo para la gran mayoría que, según los criterios de la política pública, no alcanzan a ser pilos/as.

Ahora bien, debido a esta baja cobertura y otras críticas -que se desarrollan a continuación- se ejecutaron cambios para mejorar el programa, los cuales se pueden observar en la Tabla 1:

TABLA 1

Evolución del programa SPP: condiciones, versiones y cambios introducidos

\begin{tabular}{|c|c|}
\hline Ser Pilo Paga 1 (9189 beneficiarios) & Ser Pilo Paga 3 ( 8759 beneficiarios) \\
\hline $\begin{array}{l}\text { - Obtener un puntaje igual o superior a } 310 \text { en la prueba } \\
\text { Saber } 11 \text {. } \\
\text { - Haber sido admitido en una IES de alta calidad o en proceso } \\
\text { de renovación de la acreditación. } \\
\text { - Estar registrado en la versión III del SISBEN con un puntaje } \\
\text { máximo de } 57,21 \text { para las } 14 \text { ciudades principales del país, } \\
56,32 \text { para las otras áreas urbanas y 40,75 para el sector } \\
\text { rural. } \\
\text { - Se otorga un subsidio de sostenimiento: un salario mínimo } \\
\text { mensual para los estudiantes que no tengan que desplazarse } \\
\text { de su lugar de residencia, } 1,5 \text { salarios mínimos mensuales para } \\
\text { quienes se desplacen de su lugar de residencia hacia áreas } \\
\text { metropolitanas y cuatro salarios minimos mensuales para los } \\
\text { que se desplacen de su lugar de residencia hacia lugares que } \\
\text { no correspondan a áreas metropolitanas. }\end{array}$ & $\begin{array}{l}\text { - El puntaje mínimo en la prueba Saber } 11 \text { pasó de } 318 \text { a } 342 \text {. } \\
\text { - Se suspenden los desembolsos de dinero del programa si el } \\
\text { estudiantado obtiene un promedio académico acumulado inferior al } \\
\text { exigido por la IES. } \\
\text { - Los estudiantes que no hayan culminado su formación en el } \\
\text { número de periodos que fija el programa académico escogido, } \\
\text { pueden pedir hasta dos periodos de gracia para terminar los } \\
\text { estudios y obtener el título profesional. }\end{array}$ \\
\hline Ser Pilo Paga 2 (12 115 beneficiarios) & Ser Pilo Paga 4 (8029 beneficiarios) \\
\hline $\begin{array}{l}\text { - Quedó explícito que una de las condiciones para ser } \\
\text { beneficiario es ser colombiano. } \\
\text { - Es necesario ser bachiller graduado en el año de la } \\
\text { convocatoria. } \\
\text { - El puntaje mínimo en la prueba Saber } 11 \text { pasó de } 310 \text { a } 318 \text {. } \\
\text { - Se puede cambiar de carrera máximo en el segundo periodo } \\
\text { académico de estudio. En la versión anterior, se podia hacer el } \\
\text { cambio hasta en cuarto periodo. } \\
\text { - Se incluye un periodo de gracia para los estudiantes que no } \\
\text { se hayan graduado a pesar de que el programa ya hiciera } \\
\text { todos los desembolsos. } \\
\text { - Se añadió un capitulo para estudiantes que hagan parte de } \\
\text { las Fuerzas Militares y la Policía. } \\
\text { - Se adicionó un capitulo especial para Ser Pilo Paga Profe, el } \\
\text { cual busca el ingreso de jóvenes a programas de licenciatura. } \\
\text { - Se estableció un modelo para estimar el costo de un } \\
\text { estudiante de pregrado en una IEs de alta calidad pública. }\end{array}$ & $\begin{array}{l}\text { - El puntaje mínimo en la prueba Saber } 11 \text { pasó de } 342 \text { a } 348 \text {. } \\
\text { - Hay dos capitulos especiales: Pilos por Mocoa, que beneficiará a } \\
51 \text { jóvenes de la capital de Putumayo (el puntaje es de mínimo } 313 \\
\text { puntos), y Todos somos PAZcífico, que impulsa el desarrollo de la } \\
\text { región pacífica otorgando } 158 \text { cupos (el puntaje mínimo es de } 318 \text { ). } \\
\text { - Se busca que mínimo el } 30 \% \text { de los jóvenes ingresen a } \\
\text { universidades públicas. Para lograrlo hay varios incentivos: plazo } \\
\text { de dos semestres después de graduarse del colegio para aplicar al } \\
\text { programa, inscripción gratuita para presentarse en todas las } \\
\text { universidades públicas que hacen parte de Ser Pilo Paga y medio } \\
\text { salario mínimo como incentivo adicional al apoyo de sostenimiento. } \\
\text { - Se redefinirá la metodología para calcular el valor que se les } \\
\text { pagará a las instituciones públicas por cada estudiante de SPP } \\
\text { admitido. } \\
\text { - Las universidades privadas se comprometerán a que el valor } \\
\text { anual de las matrículas para los estudiantes de SPP no crecerá por } \\
\text { encima del Índice de costos de la Educación Superior. }\end{array}$ \\
\hline
\end{tabular}

Fuente: Mora y Múnera (2018, p. 118).

Entre los cambios más destacados, puede resaltarse la puntuación para alcanzar a ser pilo/a, la descentralización geográfica creciente de los/as posibles beneficiarios/as, así comolas posibilidades de obtener un tiempo adicional para terminar los estudios y no caer en cláusulas moratorias asfixiantes. Para terminar de redondear la historia reciente del programa, es importante explicitar las críticas más importantes a las versiones de SPP.

Entonces, entre 2015 y 2018, fueron 40.000 los/as pilos/as beneficiados/as, que significan alrededor del $2 \%$ de la cantidad de jóvenes de estrato 1, 2 y 3 que necesitan apoyo para continuar sus estudios. Aunque sin duda destinar esta cantidad de dinero ha sido importante, en comparación a otros usos puede resultar ineficiente. En otras palabras,

Sin embargo, los estimativos de los investigadores Gómez y Asmar son que, para el año 2018, los recursos girados al programa serán los mismos que reciben por transferencia las 32 universidades públicas nacionales y regionales. Con la diferencia de que en estas estudian 655.000 jóvenes. Es decir que el Estado invertirá para el año 2018 la misma cantidad de dinero en los 
'pilos' que en los 655.000 estudiantes de todas las universidades públicas del país. ¿Es esto justo? ¿Es eso conveniente? (De Zubiría, 2016, p. 3).

Esta cuestión central ha sido medianamente defendida en función de que antes no existía ningún programa con esas particularidades. Es decir, según Álvarez, et al. (2017) y Londoño, (2016) peor sería que no existiera nada. Aunque es cierto que el esfuerzo gubernamental es de valorar en tanto no se desliga el Estado de relativamente garantizar la educación a más personas, es insuficiente y demasiado selectivo. Resulta muy amplio el filtro de lo meritocrático al reducirlo a una puntuación en unas pruebas de Estado, cuando sin duda existen ciertos condicionamientos desde la educación básica y secundaria, así como cuestiones materiales y familiares que no facilitan competir en condiciones similares al estudiantado ${ }^{[7]}$.

Otra de las críticas es la necesidad de que las IES que hacen parte del programa deben ser acreditadas como de alta calidad por parte del Ministerio de Educación Nacional. A primera vista esto parece ser coherente, en tanto mejores estudiantes pasan a las mejores IES. No obstante, sucede que estas instituciones acreditadas están principalmente en ciudades centrales o no periféricas de Colombia.

De las 39 instituciones acreditadas que representan solo 13.6\% del total de instituciones de educación superior del país, 16 están en Bogotá y seis en Medellín, mientras que en otros departamentos como Choco, Meta y Nariño no existe ninguna, lo que obliga necesariamente a los jóvenes a trasladarse lejos de su lugar de origen, ocasionando además de mayores gastos económicos, el desprendimiento del núcleo familiar y difíciles procesos de adaptación a las grandes ciudades que tienen otras dinámicas (Ramos y Parra, 2017, p.15).

Aunado a ello, buena parte de los beneficiarios/as están precisamente en ciudades principales; de hecho, por esa razón en SPP 4 se crean capítulos especiales que incentiven la descentralización: "Todos somos PAZcífico [y] Pilos por Mocoa" (Mora y Múnera, 2018, p.118). Lo que se colige, según García (2018), es que SPP continúa centralizando la educación en ciertos espacios geográficos, lo cual agrega otros desafíos materiales y emocionales para quienes provienen de zonas rurales o no han vivido fuera de su núcleo familiar. Asimismo, vale indicar que de las 39 IES acreditadas 25 son privadas, lo cual es un desequilibrio notable frente a las restantes 14 IES públicas (Puentes y Virviescas, 2016). Es así que

el 90\% de los dineros desembolsados por SPP ha sido captado por universidades privadas. Esto es el reflejo de la elección de los beneficiarios del programa [...] el $80 \%$ de los estudiantes han preferido escoger estas instituciones para estudiar con los recursos públicos (Mora y Múnera, 2018, p. 121).

En contraposición a esto, revelan Álvarez et al., (2017), algunos defensores del programa SPP expresan que primero está la decisión individual, cimentada en el mérito, particularmente en la propensión de elegir universidades privadas o públicas (Belleï, 2002; Kerbo, 2004). Sin embargo, el dilema surge cuando se trata de dineros públicos, los cuales se están transfiriendo en buena medida a instituciones privadas y, en su mayoría, muy costosas ${ }^{[8]}$. Es por ello que SPP 3 y 4 tratan de matizar la participación de las universidades privadas y de regular sus matrículas.

Como puede notarse en la Tabla 1, para mantener su beca los pilos/as deben sostener un promedio académico alto, asimismo, si desisten de estudiar o pierden su cupo por mal desempeño deben pagar los desembolsos de la beca mediante deuda estatal, con los compromisos financieros que conllevan (Puentes y Virviescas, 2016). Al respecto, surgieron críticas por el desamparo a los/as beneficiarios/as en su proceso estudiantil. Frente a ello, algunas IES han tomado partido por generar políticas de acompañamiento como el programa de la Universidad del Valle llamado ASES, con el cual se quiere

acompañar a los estudiantes de primeros semestres, beneficiarios de SPP y admitidos por Condición de Excepción a la Universidad del Valle, en su adaptación, aprovechamiento y disfrute de la vida universitaria. Su intención es una estancia estudiantil amena, con buenos resultados académicos y que finalmente los estudiantes se movilicen hacia el éxito académico y la realización personal (Romero, 2018, p. 8). 
En el mismo sentido, la Universidad de los Andes tiene el programa institucional Sociedad Pilo, el cual tiene fines parecidos al ASES de la Universidad del Valle. Además, este convive con otro programa de esta universidad llamado Andar:

El primero es 'una red de apoyo a estudiantes con programas de beca y financiación [...]. Oficialmente fue creada el 7 de noviembre de 2013, y desde ese momento, ha venido ampliando su campo de acción y sus miembros'. Una de las estrategias de Andar es el programa de padrinazgo. (Romero, 2018, p. 9).

Este tipo de programas, que otras IES están tratando de replicar, se plantean como promotores de una vida universitaria más cómoda, con mejor desempeño académico y no estigmatizada por la condición de becados (Solano, 2008). Sin embargo, todavía es deuda del programa canales sistemáticos para que el proceso de adaptación y desempeño académico sea mejor y, en el peor de los casos, quienes tienen la beca no la pierdan y deban pagar las consecuencias de no terminar su carrera.

Aunque hay más discusión y otros fuertes debates en torno al programa, como exponen Arrubla y Uribe (2015) respecto a cuestionamientos a la eficiencia de este como política pública, la relación con mayor calidad académica ${ }^{[9]}$, así como el propio instrumento utilizado para elegir a los pilos/as ${ }^{[10]}$, lo interesante de las desarrolladas anteriormente es que son relevantes en el tema principal de este texto. Es decir, beneficiarios/ as que responden a nuevas realidades en cuanto a su experiencia de vida, variaciones a una vida universitaria en microclimas conformados, grosso modo, por otra clase social. En otras palabras, fronteras de clase social que se ponen en tensión en virtud de que "los estudiantes de clase baja [que] se confrontan mucho más con la desigualdad y esto los hace ser más conscientes de asuntos de clase, más incómodos, intimidados, inadecuados, deficientes y excluidos que en la universidad pública” (Álvarez, 2019, p. 8).

\section{Aproximación a tensiones de Clase Social EN SPP}

Si las personas beneficiarias han sido un porcentaje reducido respecto a la totalidad de quienes aspiran a una IES, también lo son las que han escogido instituciones educativas públicas, en su mayoría han optado por privadas. En otras palabras,

el 90\% de los dineros desembolsados por SPP ha sido captado por universidades privadas. Esto es el reflejo de la elección de los beneficiarios del programa, [...] el 80\% de los estudiantes han preferido escoger estas instituciones para estudiar con los recursos públicos (Mora y Múnera, 2018, p.121).

La particularidad, sostiene De Zubiría (2016), es que 8 de cada 10 estudiantes han optado por una IES privada que, en muchas ocasiones, se sitúa en las grandes ciudades del país. Ahora bien, no existe una única causa para explicar estas decisiones: vinculadas a la alta valoración de lo privado sobre lo público de larga data en el país (Sánchez y Otero, 2012), decisiones individuales ligadas al prestigio institucional particular (Rama, 1970) y sensaciones de ascenso social que pueden observarse en estudios como los de Díaz (2012) y Vizcaíno y Amaya (2006). Asimismo, es posible apoyarse de cierta forma en una propensión de aspirar a la cultura legítima (Bourdieu y Passeron, 1977; Sandoval, 2011) que oficia como eje de valoración y en el que las instituciones privadas están en el rango más alto. Ahora bien, esta relación vertical muchas veces no permite dar margen a las libertades individuales que, en ciertos casos, eligen desde otras aristas o vinculaciones que no necesariamente atañen a esa legitimidad rígida; en el desarrollo de las entrevistas se podrá ver que la cuestión toma más artistas que una legitimidad unívoca de clase social.

Dando paso a algunas situaciones concretas. Saber un segundo idioma - que para colegios/secundarios privados o públicos de muy buena calidad es común — para algunos pilos/as egresados de colegios de calidad media o baja es una barrera: apenas saben lo mínimo o casi nada de otro idioma al de la lengua materna. De hecho, "[el nivel de] inglés [en colegios oficiales/estatales] es muy bajo: ninguno de los 250 mejores colegios 
en inglés es de carácter oficial" (Romero, 2018, p. 5). En este sentido, casos de pilos como David y Carolina son dicientes:

\begin{abstract}
Hubo una clase del curso Historia y Filosofía de la Ciencia para la que nos pusieron una lectura como de 100 páginas en inglés. 'Era pura Antropología. [...] Pasé varias noches con el traductor de Google tratando de hacerla', recuerda David, un pilo de La Tebaida (Quindío) que está a punto de terminar el pregrado de Filosofía en Los Andes. [...] Carolina aún tiene en la memoria la vez en que le tocó leer 'un título de una lectura en inglés', la forma incorrecta en que pronunció y la vergüenza que tuvo. (Romero, 2018, p. 5)
\end{abstract}

Esta diferenciación, que en el fondo guarda distanciamientos sociales de tipo estructural, presenta para los pilos/as un reto adicional que, en algunos casos, puede ser vergonzoso (Carolina), traumático (David) o, en otros, de desconcierto ${ }^{[11]}$. En esta perspectiva de fronteras sociales sutiles o suaves, a Ana Sofía, por ejemplo, le pasó con Mariana, una chica de plata que no sabía si Ana era becada o no, que comenzó ese día a llamarla Sofi. "Otra cosa característica de esta universidad — cuenta Ana Sof í a- es que la gente de plata le pone a uno el diminutivo del nombre, 'Sofi'. O sea, en mi colegio nunca en la vida, ijamás!” (Álvarez, 2019, p. 2).

De igual manera, un joven llamado Daniel comentaba que cambió su forma de vestir tratando que su nueva ropa no parezca de imitación, incluso gastó una considerable cantidad de dinero en adquirir una maleta de diseñador en un reconocido centro comercial en aras de pertenecer, de asimilarse a su nuevo grupo. "Daniel no quiere que nadie sepa que es becado. Quiero que piensen cuando me miren, 'él paga"', me cuenta. (Álvarez, 2019 , p. 14). Tanto Daniel como Sofía comentaron que sintieron vergüenza de decir en qué lugar de la ciudad viven, prefirieron esconderlo a sus compañeros/as que viven en zonas acomodadas.

Así entonces, existen representaciones de diferenciación blanda o suave en círculos de compañerismo de los sectores medios-altos y altos que, para los beneficiarios/as del programa, presentan novedosos contornos a afrontar; marcados por recursos materiales limitados -en el caso de acceso a colegios con buen inglés o determinada indumentaria - o simbólicos -el abreviar el nombre- (Pons et al., 2000). Si bien estas cuestiones no parecen ser del todo traumáticas o expulsivas, dibujan un ambiente diferenciado, algo disímil que enfrenta a modos o estilos de vida distintos. Entornos lejanos de un punto de partida igualitario en una hipotética sociedad de equidad de oportunidades, en donde las destrezas y habilidades individuales son la bisagra entre triunfar o fracasar (Kerbo, 2004). No obstante, esto no quiere decir entornos necesariamente incongruentes o desprovistos de toda sociabilidad (Solano, 2008).

Ahora bien, otros casos ligados a mayores abismos estructurales han resultado verdaderamente problemáticos, con desenlaces desastrosos. Ejemplo de ello es el caso de David Cruz, quien

Tenía 15 años cuando creía que estudiar Finanzas y Contaduría en la Universidad Icesi de Cali, gracias a Ser Pilo Paga, era como ganarse la lotería. Hoy, a sus 19 años, asegura que fue la peor pesadilla. Terminó como un desertor por ingresar a un programa que no lo apasionaba y con una deuda de \$38 millones [cifra en peso colombiano] (SemanaEducación, 2019, párr. 32).

Este beneficio comenzó como una gran ilusión para su madre, quien le recomendó que estudiara lo que le apasionara pero que no olvidara que ella dependía de él. Este joven residente de Aguablanca (Cali) explica que nunca se acopló por la mala formación en su secundario, principalmente en el área de matemáticas y que por un grave problema de salud de la madre tuvo que desistir de seguir estudiando. A sus 19 años, después de pagar una cuantiosa deuda con el Estado contraída por incumplir su contrato de terminar la carrera universitaria, anhela volver a estudiar lo que de verdad le apasiona: la música.

Los dilemas económicos y familiares de sectores bajos, como el caso de David Cruz, contrastan con problemáticas relativamente saldadas para sectores medios-altos y altos. En otras palabras, "antes de individualizar sus propias aspiraciones y proyectos se sienten llamados a retribuir a sus padres el apoyo de ellos recibido y contribuir a mejorar la situación económica de sus padres y hermanos" (Arango et al., 2004 citado por López y Moncada, 2012, p. 398). Sin embargo, no se quiere expresar que estas situaciones estructurales 
repercuten de la misma forma en todos/as los pertenecientes a estos sectores sociales. El caso de Jorge Arias, un joven de una localidad popular de Bogotá,

Con tan solo 21 años, es profesional en Lenguas Modernas con énfasis en Comunicación Organizacional de la Universidad
EAN. Trabaja en Burson Cohn \& Wolfe, una de las agencias de relaciones públicas y comunicaciones más grandes del
mundo. Tiene una banda de indie-pop llamada Alex Valens. Y espera en menos de dos años hacer una maestría en Gestión
Cultural en Italia. Emocionado, asegura que, como muchos otros jóvenes, no hubiera llegado tan lejos sin la beca condonable
de Ser Pilo Paga. (SemanaEducación, 2019, párr. 21).

Estos casos exitosos de SPP sin duda cuestionan investigaciones como las de los ambientes educativos caóticos presentadas en los excluidos del interior, la extensa obra de Pons et al., (2000). En ella se exhiben un mosaico casi que desértico de futuro en secundarios de sectores populares de algunas localidades francesas. En contrapartida, Solano (2008) y Álvarez (2019) se apoyan en que, aunque sin duda perviven microclimas propios en los ambientes estudiantiles de sectores medios altos y altos, las personas beneficiarias de SPP no han sido sistemáticamente expulsadas o relegadas. De cierta forma, se han agrandado los niveles de tolerancia que permiten, en cierto sentido, una vida universitaria más acorde para conseguir sus metas. Tal vez este sea el caso de Jorge Arias - uno de varios que seguramente hay en este sent i do — el cual ofrece un panorama conjunto de cualidades o destrezas sobresalientes, condiciones familiares y vínculos de compañerismo particularmente acordes que posibilitan que salgan victoriosos ante este tipo de oportunidades y retos. Es decir, lo que a primera vista puede parecer una imposibilidad, una reproducción de lo que le sucedió a David Cruz en el testimonio anterior, toma un rumbo victorioso a pesar de todo, triunfa ${ }^{[12]}$.

Con todo, no necesariamente las fronteras y posibilidades de clase social se evidencian en la deserción, la imposibilidad de permanencia durante toda una carrera — casi siempre de cinco años — además de otros desafíos familiares por insolvencia económica. Por ello, es interesante volver a explicitar algunas cuestiones de identificación/diferenciación de clase que, guardando proporciones, podrían ubicarse dentro de un ámbito más situacional o contextual. Ejemplo de ello es lo sucedido a un joven que, mediante comunicación telefónica anónima con SemanaEducación (2019), expresó “siempre estuve en el lugar equivocado" (párr. 17). Al ser un joven de una zona periférica de Cali, graduado de un colegio secundario de medio o bajo nivel educativo y consciente de que la situación familiar socioeconómicamente era ajustada, terminó por expresar: "Todo fue por mi culpa. Desaproveché la oportunidad que me dieron por fiestero. Porque, incluso la plata que me entregaban para mi sostenimiento la despilfarré" (párr. 17).

Esta propensión a la autoculpabilización, a la aseveración de que no era/es para mí se ve potenciada en algunas ocasiones por los no-becados/as. Varios y varias, según Álvarez (2019), "Mencionaron que 'les dan demasiado', que 'acumulan subsidios' (transferencias condicionadas, ayudas del gobierno y de la universidad) y que 'gastan en cosas innecesarias' como un 'partido de fútbol' o unos 'tenis carísimos'” (p. 18). En otras palabras, en el mismo texto de Álvarez (2019), un estudiante de ingeniería de clase alta resumió la actitud de varios de su clase: "Profe, aquí es claro quién no es becado, pero no es tan claro quién es becado" (p. 2). La cuestión no solo radica en procesos de largo o mediano plazo sino en vínculos cotidianos que ofician como excluyentes o incluyentes. Si bien existen procesos particulares, relativo a universidades de élite, privadas de bajo prestigio o públicas, lo que más ha resaltado en estos estudios de clase social ha sido cuando estudiantes pilos/as ingresan a universidad dirigidas a las élites y/o personas de clase media-alta o alta. Las tensiones de clase sociales se hacen un poco más transparentes y, ya sea desde autoculpabilización, problemáticas materiales, familiares o propias de la vida universitaria, influyen en aflorar una sociedad relativamente excluyente, con programa limitados como el mismo SSP, atada a desigualdades que se resisten y, por tanto, presentando condiciones de diferenciación negativa para los pilos/as en su estancia en una IES que, como se expresó anteriormente, todavía la política pública no enfrenta de manera decidida. 


\section{Comentarios finales}

Ana Sofía, al ser invitada a la casa de una de sus compañeras de carrera de una universidad de élite de Bogotá, expresaba que la madre de su colega no hacía nada: solamente limpiaba porcelanas y otros pequeños quehaceres. De forma comparativa, encontraba rasgos muy diferentes a lo ejecutado cotidianamente por su madre en su hogar, en donde — decí a - el extenso trabajo doméstico es la regla. Al saber el colegio al que asistió su compañera no podía creer de lo que estaba dotado: amplio césped, salón de debate, salón de ballet, casillero propio, baños impecables y una decoración majestuosa. Al citar este recuento en su entrevista, sintetizaba:

Yo decía, claro, la vida de ellos es, o sea, salir de un colegio así e ir a una casa y con carro [automóvil]. O sea, no sé qué otra comodidad. A uno le toca transporte público, pero yo no sentía odio, yo me sentía feliz de conocer eso en la vida real, eso existe en la vida real. O sea, no eran solamente las películas. (Álvarez, 2019, p. 13).

La vida de esta familia era otra. Ana Sofía expresa muy bien los distanciamientos de clase social. Actividades y usos de tiempos distintos, comodidades diferentes, formas de ver el mundo que para su compañera son normales y para ella son de película. Lo que sin duda tiene SPP es que ha desarrollado cierto alumbramiento de una sociedad muy desigual, ha iluminado, a partir de un contexto de vida universitaria, algunas de las diferentes comodidades materiales y fronteras simbólicas que estructuran a las clases sociales colombianas. Juntando a personas de sectores medios-bajos y bajos con muy buenos rendimientos académicos, los denominados pilos/as, con jóvenes de clase media-alta y alta. Cabe recordar que esto sucede gracias a que los beneficiarios/as del programa estatal pueden elegir, de las IES acreditadas, la IES que deseen.

La afirmación anterior no quiere expresar que el programa solo configura un escenario de puesta en acción de dos clases sociales excluyentes o posiciones sociales tan dispares que se rechazan como polos opuestos; como podría desprenderse del estudio de clases sociales y educación en Colombia de Cataño (1984). Sino que también existen casos de acoplamiento o asimilación en los nuevos escenarios compartidos entre pilos/as y compañeros/as universitarios (Díaz, 2012; Solano, 2008). De lo que no cabe duda es que SPP da la posibilidad empírica de transparentar algunos de los límites materiales y las fronteras simbólicas de clase social de la que está compuesta la sociedad colombiana. Sin ánimo de abstraer las particularidades y las situaciones concretas, este texto se aproxima, desde los testimonios citados, a las interacciones sociales y a ciertos condicionamientos macrosociales que configuran mundos sociales disímiles.

Paradójicamente este programa surge desde la esfera del sistema educativo, en donde, como profesa el propio SPP, la educación se presenta como puente de movilidad social. En este sentido, lo que no puede desconocerse es que las condiciones entre educación pública y privada, apoyo material y emocional familiar, así como destrezas y voluntades individuales, juegan papeles importantes en la vida universitaria de cualquier joven. Si se aterriza a un contexto en que no solo la educación parece otra, lejana en términos de calidad, idioma, sino también el cambio de residencia y nuevos compañeros/as y ambientes de sociabilidad, las desigualdades e identificaciones de clase social se hacen más evidentes; casi que se presentan de forma inaudita en una sociedad altamente segmentada y excluyente. Es decir, probablemente hubiese sido más difícil o remoto para estos pilos/as una vinculación de esas magnitudes con sus compañeros/as por fuera de un ambiente educativo, puesto que en general sus formas de habitar la ciudad, residencia familiar, consumos, entre otras cosas, son diferentes y, como estructurantes de clase social, muchas veces discrepan (Bourdieu, 1984).

Por último, sin duda es imposible dejar de sorprenderse que el programa SPP, en virtud de acercar la continuidad de educación superior a sectores de estratos medio-bajos y bajos, se haya diseñado para alcanzar solo poco más de $2 \%$ de todos los y las estudiantes que se han graduado entre los años 2015 y 2018 . Asimismo, que los primeros pilotos del programa se hayan centralizado fuertemente en ciudades capitales; que se hayan tardado tanto en regular la elección hacia instituciones privadas, puesto que sus fondos son públicos y esa 
cantidad de dinero pudo ser más eficiente en la educación pública, son preocupaciones válidas que precisan De Zubiría (2016) y Mora y Múnera (2018).

En suma, como se ha expuesto, SPP ha entregado una especie de informe de clase social: el país de los sectores medios-bajos y bajos, según Marcos (2018) algo así como el 80\% de la población de Bogotá - parecido sucede a nivel nacional - pertenecen a los estratos 1,2 y 3 , es bastante distinto al de los medios-altos y altos. Aunque esto parece una obviedad, no lo es tanto cuando Colombia se ubica entre los países más desiguales del mundo y las posibilidades de ascenso social son extremadamente preocupantes ${ }^{[13]}$. Además de la larga lista de críticas a la política pública particular, este tipo de análisis tal vez también es útil para redescubrir, así como Ana Sofía con la vida de su compañera, que algunos viven de película Hollywoodense y a otros solo les alcanza para vivir en una película tipo B, de bajo presupuesto.

\section{Referencias Bibliográficas}

Álvarez, M. (2019). ¿"Los becados con los becados y los ricos con los ricos"? Interacciones entre clases sociales distintas en una universidad de elite. Desacatos, (59), 50-67. doi: https://doi.org/10.29340/59.2049

Álvarez, M., Castro, C., Corredor, J., Londoño, J., Maldonado, C., Rodríguez, C., Pulido, X. (2017). El Programa Ser Pilo Paga: impactos iniciales en equidad en el acceso a la educación superior y el desempeño académico. Bogotá: Universidad de los Andes, Facultad de Economía. Centro de Estudios sobre Desarrollo Económico (CEDE). Recuperado de https://bit.ly/2B33vlq

Arrubla, M., y Uribe, P. (2015). Serpilo ¿paga o cuesta?: Un análisis del programa de gobierno Ser Pilo Paga, a la luz del núcleo esencial del derecho fundamental a la educación superior (Tesis de grado). Universidad EAFIT, Medellín, Colombia. Recuperado de https://bit.ly/2zsPeOL

Belleï, C. (2002), ¿HHa tenido impacto la Reforma Educacional Chilena?”. Santiago de Chile: Proyecto CRESUR (Centro Regional de Formación Docente e Investigativa-Educativa), Ministerios de Educación de Argentina, Chile y Uruguay, Grupo Asesor Universidad de Stanford y Banco Interamericano de Desarrollo, BID. Recuperado de https://www.unicef.cl/centrodoc/escuelas_efectivas/escuela\%20efectivas.pdf

Bohorquez, O. (2016). Articulación y desarrollo del plan de gobierno "Ser Pilo Paga". Bogotá: Universidad Militar Nueva Granada. Recuperado de https://bit.ly/2M6gvcw

Bourdieu, P. (1984). La distinción. Madrid: Taurus.

Bourdieu, P. y Passeron, J. C. (1977). La reproducción. Elementos para una teoria del sistema de enseñanza. Barcelona: Laia.

Cataño, G. (1984). Educación y diferenciación social en Colombia. Revista Colombiana de Educación, 14, 39-51. doi: https://doi.org/10.17227/01203916.5108

Círculo de Estudios Latinoamericanos (CESLA). (8 de mayo de 2019). Colombia, uno de los paises con mayor brecha de ingresos en el mundo. CESLA. Recuperado de https://bit.ly/3gwj7xZ

De Zubiría, J. (18 de noviembre de 2016). Los riesgos de Ser Pilo Paga. Semana. Recuperado de https://www.seman a.com/educacion/articulo/ser-pilo-paga/505771

Díaz, C. (2012). La diversificación de la educación superior colombiana. Recuperado de https://bit.ly/2X78xpx

García, G. (2018). Impactos y contradicciones de la implementación de la política pública de "Ser Pilo Paga". Perspectivas Internacionales, 12(2), 41-62. Recuperado de https://bit.ly/2M3ylMW

García, M., y Quiroz, L. (2011). Apartheid educativo: Educación, desigualdad e inmovilidad social en Bogotá. Revista de Economía Institucional, 13(25) 137-162. Recuperado de https://revistas.uexternado.edu.co/index.php/ecoi $\mathrm{ns} /$ article/view/3028

Instituto de Estudios Urbanos (IEU). (28 de noviembre de 2016). El debate del sisben más allá de las inconsistencias palpables. Instituto de Estudios Urbanos. Recuperado de https://bit.ly/2M6gOUI

Kerbo, H. (2004). Estratificación social y desigualdad, el conflicto de clase en perspectiva histórica, comparada y global. Madrid: McGraw Hill 
Lahire, B. (1997). Sucesso escolar nos meios populares. As razões do improvável. Sao Pablo: Editora Ática.

Londoño, J. (21 de junio de 2016). ¿Qué impacto está teniendo Ser Pilo Paga en las universidades de élite en Colombia? Foco Económico. Recuperado de https://bit.ly/2X8EQ7R

López, C., y Moncada, L. (2012). Expectativas de acceso a la universidad en los jóvenes de sectores populares de Bogotá Educación y Educadores. Educación y Educadores, 15(3), 383-409. doi: https://doi.org/10.5294/edu.2012.15. 3.3

Marcos, A. (22 de abril de 2018). Los estratos en Colombia: Eres el lugar en donde vives. El País. Recuperado de ht tps://bit.ly/3gsVTcj

Mendes, A. (2016). Origen y destino: pensando la sociología reflexiva de Bourdieu. Buenos Aires: CLACSO.

Mora, A., y Múnera, L. (2018). "Ser pilo no paga”: privatización, desigualdad y desfinanciamiento de la universidad pública en Colombia. Ciencia Politica, 14(27), 115-142. doi: https://doi.org/10.15446/cp.v14n27.73369

Moreno, Ó. (7 de noviembre de 2018). La fábrica del estudiante endeudado. El Espectador. Recuperado de https:// bit.ly/3ertVfb

Rama, G. (1970). Educación universitaria y movilidad social. Reclutamiento de élites en Colombia. Revista Mexicana de Sociología, 32, 861-891. Recuperado de https://bit.ly/3gwf9FV

Ramos, Y., y Parra, A. (2017). Programa "Ser pilo 1 paga" en el marco de la educación superior en Colombia. Diálogos sobre educación. Temas actuales en investigación educativa, 8(14) 1-18. Recuperado de https://bit.ly/2U1mp31

Redacción Negocios y Economía. (26 de enero de 2016). La desigualdad en Colombia es una de las más altas del mundo. El Espectador. Recuperado de https://bit.ly/2X6CDcX

Redacción El Tiempo. (5 de agosto de 2000a). Así nació el Icetex. El Tiempo. Recuperado de https://www.eltiempo .com/archivo/documento/MAM-1242065

Redacción El Tiempo. (26 de septiembre de 2000b). Por un préstamo nació el Icetex. El Tiempo. Recuperado de htt ps://www.eltiempo.com/archivo/documento/MAM-1211841

Romero, J. (15 de octubre de 2018). El choque social de los pilos. Cerosetenta. Recuperado de https://cerosetenta.un iandes.edu.co/el-choque-social-de-los-pilos/

Pons, H., Accardo, A., Balazs, G., Beaud, S., Bourdieu, E., Bourgois, P., Wacquant, L. (2000). La miseria del mundo. Buenos Aires: Fondo de Cultura Económica.

Poveda, S. (2019). Análisis de las representaciones sociales de los territorios de origen y recepción, en el caso de los beneficiarios delprograma Ser Pilo Paga en condición de migrantes en la ciudad de Bogotá. (Tesis de grado). Bogotá: Universidad Santo Tomás [usta]. Recuperado de https://repository.usta.edu.co/handle/11634/17705

Puentes, C., y Virviescas, L. M. (2016). La relación acreedor-deudor en el sistema de educación superior en colombia: Un análisis de la pedagogía de la deuda-programa "Ser Pilo Paga"(Tesis de maestría). Pontifica Universidad Javeriana, Bogotá. Recuperado de https://bit.ly/2yEGnJb

Salazar, N., Mesa, C., y Correa, C. (2016). Financiación de la Educación Superior a través del Icetex: Estimación de necesidades de recursos a futuro y porpuestas de mecanismos de fondeo. Bogotá: FEDESARROLLO.

Sánchez, A. y Otero, A. (2012). Educación y reproducción de la desigualdad en Colombia. Reportes del Emisor, (54), 1-4. Recuperado de https://bit.ly/2TKACAS

Sandoval, M. (2011). Promoción automática y competencias como reproducción de las desigualdades en el campo educativo colombiano. En Ramírez y Peña. Cultura, educación y sociedad en tiempos de crisis: desde la perspectiva de Pierre Bourdieu. Bogotá: Universidad Militar Nueva Granada.

Sarmiento, L. (22 de octubre de 2014). Colombia: colonialismo y consumo siglo XXI. Desdeabajo. Recuperado de h ttps://bit.ly/2ZHsKUD

Semana. (30 de noviembre de 2019). Las generaciones necesarias para que un colombiano deje de ser pobre. Semana. Recuperado de https://bit.ly/2TLQ8g3

SemanaEducación. (25 de febrero de 2019). ¿Pagó ser "pilo"?: historias que revelan la realidad de este programa. Semana. Recuperado de https://bit.ly/2M1Gt0J 
Solano, J. C. (2008). La exclusión social a través de la desigualdad de oportunidades educativas. En Hernández Pedreño. Exclusión social y desigualdad. España: Ediciones de la Universidad de Murcia.

Uribe, C. (2008). Estratificación social en Bogotá: de la política pública a la dinámica de la segregación social. Universitas Humanistica, 65(65), 139-171. Recuperado de https://bit.ly/2X6UuQU

Vega, L. (4 de julio de 2019). Las versiones de los jóvenes que acceden a créditos con el Icetex. Radio Nacional de Colombia. Recuperado de https://bit.ly/3c3Xphy

Villarraga, A. (2017). Ser Pilo Paga: Innovación en las estrategias de financiamiento a la demanda de Educación Superior en Colombia. Revista de Educación Superior en América Latina, 1, 1-2. Recuperado de http://rcientif icas.uninorte.edu.co/index.php/esal/article/view/9426

Vizcaíno, M. y Amaya, J. (2006). Universidad, exclusión y desigualdad. Bogotá: Universidad Cooperativa de Colombia.

\section{Notas}

[1] La palabra pilo significa inteligente, de un alto intelecto, para Colombia.

[2] A inicios de la década de 1980 [los asalariados se] apropiaban el 44\% y actualmente solo el 32\%, es decir, en las tres últimas décadas los asalariados perdieron 12 puntos en la participación de la riqueza producida anualmente en el país, bien por caída en los salarios o por desplome del trabajo asalariado (remplazado por formas precarias e inestables de trabajo, esto es, la diversidad del rebusque o informalidad: microempresarios, cuenta propia, trabajadores familiares no remunerados, etc.) (Sarmiento, 2014, p. 3).

[3] Cada año logran acceder a la educación superior alrededor de dos millones doscientos ochenta mil jóvenes de entre 17 y 21 años, que es el 52\% del total de estudiantes que se encuentran en el país; según cifras del Ministerio de Educación. [...] La mitad de esos jóvenes que no ingresan a universidades públicas deciden endeudarse con el Instituto Colombiano de Crédito Educativo y Estudios Técnicos en el Exterior, Icetex; es decir, alrededor de 630.000 jóvenes, lo que significa que más del 14\% de ellos tienen algún tipo de servicio activo con esta entidad (Vega, 2019, p. 1-2).

[4] De acuerdo con Fernando Luis Calao, presidente de la Asociación de Usuarios de Icetex (Acupe), las deudas con el Icetex se vuelven impagables y se presentan casos de anatocismo, o acción de cobrar intereses sobre los intereses de mora derivados del no pago de un préstamo. Lo que se pasa por alto, sin embargo, es una coincidencia inquietante: el microcrédito o los créditos estudiantiles han florecido precisamente cuando los Estados han abandonado los esfuerzos macroestructurales para combatir problemáticas urgentes como la pobreza, y con préstamos a pequeña escala, por tanto nunca serán resueltos. (Moreno, 2018, p. 17).

[5] Cabe recordar que

Como lo establece el Icfes (2015), el examen se compone de 235 preguntas cerradas de selección múltiple con única respuesta y ocho preguntas abiertas donde se puede obtener el crédito total, crédito parcial o sin crédito según la capacidad para responder a la pregunta; en estas preguntas no se evalúan condiciones de forma, los temas a evaluar son: matemáticas, lectura crítica, sociales y ciudadanas, ciencias naturales, inglés, competencias ciudadanas y razonamiento cuantitativo. (Ramos y Parra, 2017, p.11).

[6] "El Sistema de Beneficiarios para Programas Sociales (SISBEN) es una herramienta, conformada por un conjunto de reglas, normas y procedimientos para obtener información socioeconómica confiable y actualizada de grupos específicos en todos los departamentos, distritos y municipios del país" (Instituto de Estudios Urbanos [IEU], 2016, párr. 1).

[7] Por ejemplo,

el promedio de edad y la proporción de hombres en el grupo de beneficiarios y sus compañeros es muy similar. Por su parte, la educación de los padres muestra diferencias significativas. Mientras que alrededor del $65 \%$ de madres y padres de los jóvenes beneficiarios alcanzan educación secundaria o menos, esta proporción es cercana a 40\% para los otros alumnos de IES acreditadas. Asimismo, solo el 18\% de los padres de los tratados alcanzan educación superior mientras que más del $40 \%$ de los padres de sus compañeros alcanzan este nivel educativo (Álvarez, et al., 2017, p.49-50).

[8] El valor promedio de matrícula por semestre de un estudiante en la Universidad de los Andes [Universidad de élite de las más reconocidas en Colombia y Latinoamérica] (la cual ha recibido 1.261 'pilos' en total) asciende a 13493075 pesos COP [aprox. Unos 4.000 dólares a diciembre de 2019], mientras que en la Universidad Nacional de Colombia dicho valor es de 378762 pesos COP [aprox. Unos 112 dólares a diciembre de 2019] por estudiante (institución que solo ha recibido 837 estudiantes) (Ramos y Parra, 2017, p.12). 
[9] En cuanto a esto, parece ser que no necesariamente es directa la relación entre SPP y una competencia sana o virtuosa para mejorar rendimientos académicos. De ahí que

durante los 3 años del programa podemos concluir que eso - por lo menos hasta el momento-solo es parcialmente válido. Del primero al segundo año, el impacto en las pruebas SABER 11 fue nulo y del segundo al tercero, mejoramos 1,4 sobre 100. Lo que implica que el incremento promedio ha sido de 0,7 por año, crecimiento marginal y que no puede ser atribuido exclusivamente a SPP, ya que, simultáneamente hay múltiples programas de política pública en curso, como Aliados 10, la jornada única o el PTA, entre muchos otros. (De Zubiría, 2016, p.6).

[10] En esta perspectiva, “Como lo indican Asmar y Gómez (2016), las pruebas Saber 11 no pueden ser mecanismos fiables que garanticen la capacidad académica de un estudiante para optar a la ES, debido a que los exámenes presentan restricciones estructurales y metodológica" (Ramos y Parra, 2017, p. 14).

[11] En este sentido, vale acotar este otro testimonio:

Yo pensaba, ‘ ¿por qué lo hacen?, ¿qué sentido tiene? Si están hablando español, ¿para qué meten palabras en otro idioma?’, narra Gisselly Moya sobre su experiencia en la Universidad Javeriana de Cali. Ella es una pila que nació y se crió en Turbo (Antioquia) y que debido a la beca se mudó a la capital del Valle. Y agrega: 'Sentía que yo no era capaz de socializar con ellos, que no teníamos nada en común. Ellos eran, por así decirlo, de la élite’ (Romero, 2018, p. 6).

[12] El libro Sucesso escolar nos meios populares. As razóes do improvável de Bernand Lahire (1997) presenta un fuerte cuestionamiento a algunas ópticas epistémicas mecánicas entre formación educativa y posición socioeconómica. Es de valorar, en este sentido, la esfera familiar como algo conjunto entre el estudiantado y la escuela, es decir, una especie de tridente que juega constantemente para producir la vida universitaria particular a pesar de ciertas condiciones semejantes o disímiles con compañeros de estudio, docentes específicos, etc.

[13] Según un informe reciente de la OCDE, Colombia necesita 11 generaciones para que una persona que nace pobre llegue a la clase media. En esta lista, "Le siguen Sudáfrica y Brasil, que necesitan 9. China, India y Hungría, 7. Francia, Alemania, Chile y Argentina, 6. Y Estados Unidos y Reino Unido, 5. Dinamarca ocupa el primer lugar, con solo 2 generaciones para dar ese salto”. (Semana, 2019, párr. 1).

\section{BY-NC-ND}

